\title{
Optimizing Treatment of Familial Hypercholesterolemia in Children and Adolescents
}

\author{
Ilse K. Luirink ${ }^{1,2,3}$ • Barbara A. Hutten ${ }^{2}$ Albert Wiegman ${ }^{1}$
}

Published online: 15 August 2015

(C) The Author(s) 2015. This article is published with open access at Springerlink.com

\begin{abstract}
Cardiovascular disease (CVD) is still the most prominent cause of death and morbidity in the world, and one of the major risk factors for developing CVD is hypercholesterolemia. Familial hypercholesterolemia (FH) is a dominantly inherited disorder characterized by markedly elevated plasma low-density lipoprotein cholesterol and premature coronary heart disease. Currently, several treatment options are available for children with FH. Lifestyle adjustments are the first step in treatment. If this is not sufficient, statins are the preferred initial pharmacological therapy and they have been proven effective and safe. However, treatment goals are often not achieved and, hence, there is a need for novel treatment options. Currently, several options are being studied in adults and first results are promising. However, studies in children are still to be awaited.
\end{abstract}

This article is part of the Topical Collection on Lipid Abnormalities and Cardiovascular Prevention

Albert Wiegman

a.wiegman@amc.uva.nl

Ilse K. Luirink

i.k.luirink@amc.uva.nl

Barbara A. Hutten

b.a.hutten@amc.uva.nl

1 Department of Pediatrics, Emma Children's Hospital, Academic Medical Center, University of Amsterdam, Meibergdreef 9, 1105 AZ Amsterdam, The Netherlands

2 Department of Clinical Epidemiology, Biostatistics and Bioinformatics, Academic Medical Center, University of Amsterdam, Meibergdreef 9, 1105 AZ Amsterdam, The Netherlands

3 Department of Vascular Medicine, Academic Medical Center, University of Amsterdam, Meibergdreef 9, 1105

AZ Amsterdam, The Netherlands
Keywords Familial hypercholesterolemia $\cdot$ Children · Adolescents · LDL cholesterol · Treatment · Novel agents

\section{Introduction}

Familial hypercholesterolemia (FH) is a common dominantly inherited disorder of lipoprotein metabolism. It is caused by mutations in genes encoding key proteins involved in the lowdensity lipoprotein receptor (LDLR) and its endocytic and recycling pathways. In the vast majority $(>90 \%), \mathrm{FH}$ is due to a loss of function mutations in the LDLR gene. In addition, FH can be caused by mutations in the apolipoprotein B (ApoB) $(5 \%)$ and proprotein convertase subtilisin-like kexin type 9 (PCSK9) (1\%) genes [1-3]. The associated decrease in the function of LDLR results in a decreased rate of lowdensity lipoprotein cholesterol (LDL-C) removal from the circulation and, thus, in an increase of plasma LDL-C.

Historically, the prevalence is estimated at 1:500 for clinical heterozygous FH (HeFH) and at 1:1.000.000 for homozygous $\mathrm{FH}(\mathrm{HoFH})$. However, recent studies suggest that the actual prevalence is higher-approximately 1:250 for HeFH

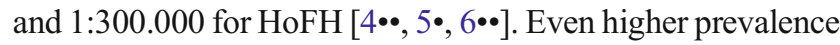
is observed in subpopulations such as Afrikaners in South Africa, French Canadians, or Christian Lebanese due to founder effects [7].

Diagnosis in children should preferably be established by detection of the FH-causing mutation, which is considered to be the gold standard for diagnosis. Genetic testing, however, is not always available. In that case, FH in children can be diagnosed phenotypically by the presence of an increased LDL-C level plus a family history of premature coronary heart disease (CHD) or elevated LDL-C levels compatible with FH (Table 1). 
Table 1 Diagnosis of familial hypercholesterolemia in children and adolescents

- Family history of premature CHD plus high LDL-C levels are the two key selective screening criteria ${ }^{\mathrm{a}}$

- Cholesterol testing should be used to make a phenotypic diagnosis

- An LDL-C level $\geq 5 \mathrm{mmol} / \mathrm{L}$ (190 mg/dL) on two occasions after a 3month diet indicates a high probability of FH. A family history of premature coronary heart disease in close relative(s) and/or baseline high cholesterol in one parent, together with an LDL-C level $\geq 4 \mathrm{mmol} /$ $\mathrm{L}(160 \mathrm{mg} / \mathrm{dL})$, indicates a high probability of $\mathrm{FH}$. If the parent has a genetic diagnosis, an LDL-C level $\geq 3.5 \mathrm{mmol} / \mathrm{L}(130 \mathrm{mg} / \mathrm{dL})$ suggests FH in the child

- Secondary causes of hypercholesterolemia should be ruled out

- DNA testing establishes the diagnosis. If a pathogenic LDLR mutation is identified in a first-degree relative, children may also be genetically tested

- If a parent died from CHD, a child even with moderate hypercholesterolemia should be tested genetically for $\mathrm{FH}$ and inherited elevation of $\mathrm{Lp}(\mathrm{a})$

${ }^{\text {a }}$ Acknowledgement to the FH Foundation (http:/thefhfoundation.org/) (with permission from [26••])

Currently, there are three strategies to consider regarding detection of FH in children: cascade screening, universal screening, or selective screening based on family history [8-10]. Different countries use different strategies, based on feasibility and opinions of local expert groups [11••]. For example, in Australia and in most European countries, cascade screening based on genetic testing is recommended, whereas in the USA, selective screening beginning at the age of 2 years and universal screening at the age of 9-11 years are advocated $[9,11 \bullet \cdot 12,13]$.

In this paper, we focus on FH. However, atherosclerosis and its clinical consequence are multifactorial in origin. Therefore, it is important in patients with FH to pay sufficient attention to all the other risk factors that constitute their total CV risk. In children and adolescents, it is essential to abstain from tobacco smoking, to exercise regularly, and to keep up with a well-balanced and healthy diet, for the primordial and primary prevention of cardiovascular disease (CVD).

This review aims to provide an overview of the current treatment options for pediatric patients with $\mathrm{FH}$ plus emerging novel agents.

\section{FH and Cardiovascular Risk}

CVD is the leading cause of death and morbidity worldwide, and an important risk factor for its development is the presence of hypercholesterolemia.

Severely elevated LDL-C levels from birth onwards accelerate the development of atherosclerotic CVD, especially CHD. Although cardiovascular events are rare in childhood, children with $\mathrm{FH}$ already show functional and morphological changes of the vessel wall $[11 \bullet, 14]$. Carotid intima-media thickness (cIMT) and flow-mediated dilatation (FMD), both surrogate markers for atherosclerosis, are respectively increased and impaired in children with FH compared to healthy controls $[14,15]$. The difference in mean cIMT between children with FH and unaffected siblings may even be significant as early as the age of 8 years as recent research shows [16 ${ }^{\bullet}$.

These findings indicate that early treatment of FH is necessary to reduce the risk of CHD later in life.

\section{Non-pharmacological Treatment}

Lifestyle interventions that focus on lowering cholesterol and reducing other known cardiovascular risk factors are the first step in treating children with FH. Important interventions are dietary change, exercise, and cessation of smoking.

The latest cardiovascular health guidelines for pediatric patients by the National Heart, Lung and Blood Institute (NHLBI) recommend the CHILD-2 diet for children with known hypercholesterolemia [12]. This is a fat-modified diet, which limits the saturated fat intake to $7 \%$ of total daily calories and cholesterol intake too less than $200 \mathrm{mg} /$ day. This has been shown to be safe and modestly effective in lowering LDL-C level [12, 17, 18].

Dietary supplementation with plant sterols or stanols might enhance LDL-C-lowering effects. However, long-term studies on effect and safety have not been completed and most studies done in children are small in size $[12,19]$. Furthermore, a recent systematic review about dietary interventions in children and adults with FH stated that no conclusions can be made about the effectiveness of a cholesterol-lowering diet or any of the other dietary interventions suggested for $\mathrm{FH}$ on the prevention of CVD [20]. Currently, the use of these substances is only recommended for children from the age of 5 years [21].

Physical activity in children with FH should be promoted. Although data on the effect in children is limited, increasing physical activity might improve fasting lipid profiles [12, 22].

Strong discouragement of smoking is important, as smoking is strongly associated with an increased risk of CVD, especially in combination with hypercholesterolemia $[11 \bullet \cdot, 23]$.

\section{Pharmacological Treatment}

Lifestyle interventions alone are rarely sufficient in children with FH. Pharmacological treatment may be considered when cholesterol levels are not significantly reduced after 3 to 6 months of leading a suitable lifestyle. 
Good evidence for an absolute or relative target does not exist in children, nor in adults. Current expert opinion recommends plasma LDL-C targets for children aged 8-10 years to be $<4 \mathrm{mmol} / \mathrm{L}$ and for children older than 10 years to be $<3.5 \mathrm{mmol} / \mathrm{L}[9,11 \bullet \bullet, 13,24,25]$. In a recent consensus paper on $\mathrm{FH}$ in children, an ideal reduction of $50 \%$ from pretreatment levels for children aged 8 to 10 years has been recommended $[26 \bullet \bullet$.

\section{Statins}

All statins competitively inhibit the enzyme HMG-CoA reductase. This is a rate-limiting enzyme in the metabolic pathway of cholesterol biosynthesis in the liver. By inhibiting this step, there is a reduction of intracellular cholesterol, which, in turn, leads to an upregulation of LDL receptors on the cell surface of hepatocytes, thus increasing LDL-C clearance from the circulation [27].

Current expert consensus recommends the initiation of statin therapy in $\mathrm{HeFH}$ between 8 and 10 years. Pravastatin is

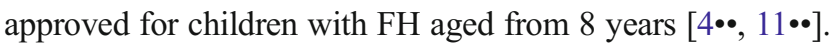
At this moment, FDA and European Medicines Agency (EMA) approval exist for simvastatin, lovastatin, atorvastatin, fluvastatin, and rosuvastatin from 10 years onwards. A recently published article shows that pitavastatin is effective and safe in children between 6 and 17 years [28]. When LDL-C levels are very high or there are additional cardiovascular risk factors, treatment needs to be initiated early [29]. Several systematic reviews and meta-analyses of statin therapy in children with $\mathrm{FH}$ have shown statins to be effective with LDL-C reductions between 21 and $39 \%$ depending on the dose and the type of statin used. In addition, they are considered safe with no significant differences in adverse events, growth, or sexual development between the statin-treated and placebo-treated children [30-32]. Furthermore, cIMT and vascular endothelial function, both markers of early atherosclerosis, improve when children with FH receive statin therapy $[14,15]$.

Adverse events are not frequent in children but can include muscle cramps, GI complaints, an increase in liver transaminase levels and, very rarely, rhabdomyolysis.

Statin treatment should be initiated at the lowest recommended dose and should only be started after two separate LDL-C measurements. It is recommended to up-titrate according to the LDL-C-lowering effect and tolerability [11••, 24, 25].

Prior to initiating statin therapy, liver transaminases, CK, and a baseline fasting lipid panel should be measured. After starting treatment, growth, weight, and physical and sexual development should be monitored [11••]. Furthermore, parents and child should be well informed about the possible side effects, so they can report any drug-related complaints in time [12]. Clinicians should be aware of drug interactions, especially with cyclosporine, erythromycin, and gemfibrozil.
When contemplating or at risk of pregnancy, adolescent girls should be counseled to stop statin treatment based on their potential teratogenic effects. A recent systematic review suggested that statins are unlikely to be teratogenic. However, large trials are lacking and the current consensus is to stop statins during pregnancy $[33,34]$.

All in all, statins are still the cornerstone of FH treatment and they appear to be safe and effective in children. However, most studies done in children had a short-term follow-up period. Recently, a study on statins with 10 years of follow-up has been published, the longest follow-up study thus far [35••]. This showed that long-term statin treatment initiated in childhood was associated with normalization of cIMT progression during aging. In terms of long-term safety, this study did not reveal a significant difference in laboratory parameters and overall statin therapy was well tolerated.

\section{Ezetimibe}

Ezetimibe is a selective cholesterol absorption inhibitor that acts at the brush border of the small intestine and inhibits the uptake of dietary and biliary cholesterol into the enterocytes. This reduces the delivery of cholesterol to the liver, which, by positive feedback, induces a compensatory increase in LDLRs, thus increasing the clearance of LDL-C from the circulation [36-38].

In adults, ezetimibe is most frequently used in combination with a statin where it provides an additional reduction of LDLC of approximately $17 \%$ and appears to be safe and well tolerated [39, 40].

A small number of short-term studies have looked at the efficacy and safety of ezetimibe in children. Both coadministered with a statin or as monotherapy, ezetimibe appears to effectively lower LDL-C without any significant side effects [41-44]. However, additional studies concerning longterm safety and efficacy are needed.

Ezetimibe $10 \mathrm{mg}$ is registered by the FDA and the EMA for pediatric use from the age of 10 years onward. Currently, the main use in children and adolescents is for those patients who either fail to achieve target LDL-C levels on a statin alone or those who are unable to tolerate (high-dose) statins due to side effects [44].

\section{Bile Acid Sequestrants}

Bile acid sequestrants (BAS) reduce plasma LDL-C by binding bile acids in the intestine and thus removing them from the enterohepatic cycle. As a result, there is an increase in the formation of bile acids from intrahepatic cholesterol. Consequently, the intracellular cholesterol concentration is reduced, which triggers the upregulation of LDLR on the surface of the hepatocyte. 
They can lower LDL-C by 10-20\%, but, owing to frequent side effects (abdominal pain, nausea, and constipation) of the classical BAS, tolerability and long-term compliance are poor in pediatric patients. These agents also interfere with the absorption of folate and fat-soluble vitamins, and appropriate dietary supplementation is recommended in children [45].

A few years ago, a second-generation BAS, colesevelam, was evaluated in children with FH [46, 47]. Colesevelam has a greater affinity for bile salts and can thus be used in lower dosage. Children experience fewer side effects, which makes the long-term adherence better.

Currently, colesevelam is the only BAS approved for the treatment of pediatric patients with $\mathrm{HeFH}$. Colesevelam comes in tablets and in powder form and can be used at dosages of 3.75 once or $1.875 \mathrm{~g}$ twice a day [48].

\section{Novel Agents}

Even though there are currently different pharmacological therapeutic options in children, target values are often difficult to achieve and maintain. Findings of a recent study in the Netherlands show that only $21 \%$ of the 1249 participating adult $\mathrm{HeFH}$ patients reached the target LDL-C levels, mainly because they were not treated with the highest dosages of statins, they are statin intolerant, or their levels were simply too high to be controlled with the current available therapy [49]. This stresses the urge for novel treatment options for patients with $\mathrm{HeFH}$.

Much is expected from the agents targeting PCSK9, antisense oligonucleotides targeting apolipoprotein $\mathrm{B}$, and microsomal triglyceride transfer protein inhibitors to reduce LDL-C beyond the levels attainable with statin monotherapy [13] (Fig. 1). The safety and efficacy results of trials with these drugs in children are still awaited [29].

\section{PCSK9 Inhibitors}

PCSK9 is a protease secreted by hepatocytes that regulates the LDLR [50, 51]. PCSK9 binds the LDLR and promotes its internalization/degradation in the hepatocyte. PCSK9 either prevents the recycling of the LDLR to the hepatocyte cell surface or it chaperones the LDLR to the lysosome where it is degraded $[11 \bullet, 50]$.

In this way, PCSK9 acts as the terminator of the long life cycle of the LDLR, which spans hundreds of recycling events [51]. Gain-of-function mutations in PCSK9 lead to a phenotype typical for $\mathrm{FH}$; conversely, dominant loss-of-function mutations result in an enhancement of LDLR activity and thus to lifelong reductions in plasma LDL-C and reduced risk of CHD [11••,50-52]. This insight led to the rationale that inhibiting PCSK9 could be a therapeutic option for patients with FH.

Monoclonal antibodies against PCSK9 are currently being studied as therapeutic agents for FH patients. These antibodies prevent PCSK from productively interacting with the LDLR on the surface of hepatocytes, thus preventing its degradation [50].

Recently, two large phase III trials have shown that evolocumab and alirocumab can lower LDL-C by, respectively, an additional $61-62 \%$ in patients with $\mathrm{HeFH}$ already treated with statins with or without other approved lipid-modifying
Fig. 1 Novel lipid-regulating drug targets. Novel drugs target either very low-density lipoprotein $(V L D L)$ production, by inhibiting apolipoprotein $\mathrm{B}$ synthesis [apolipoprotein B $(A p o B)$ antisense oligonucleotide, mipomersen] or lipid loading onto nascent ApoB [microsomal triglyceride transfer protein (MTP) inhibitor, lomitapide], or low-density lipoprotein catabolism by increasing lowdensity lipoprotein receptor recycling (PCSK9 inhibitors) (with permission $[6 \bullet \bullet]$ )

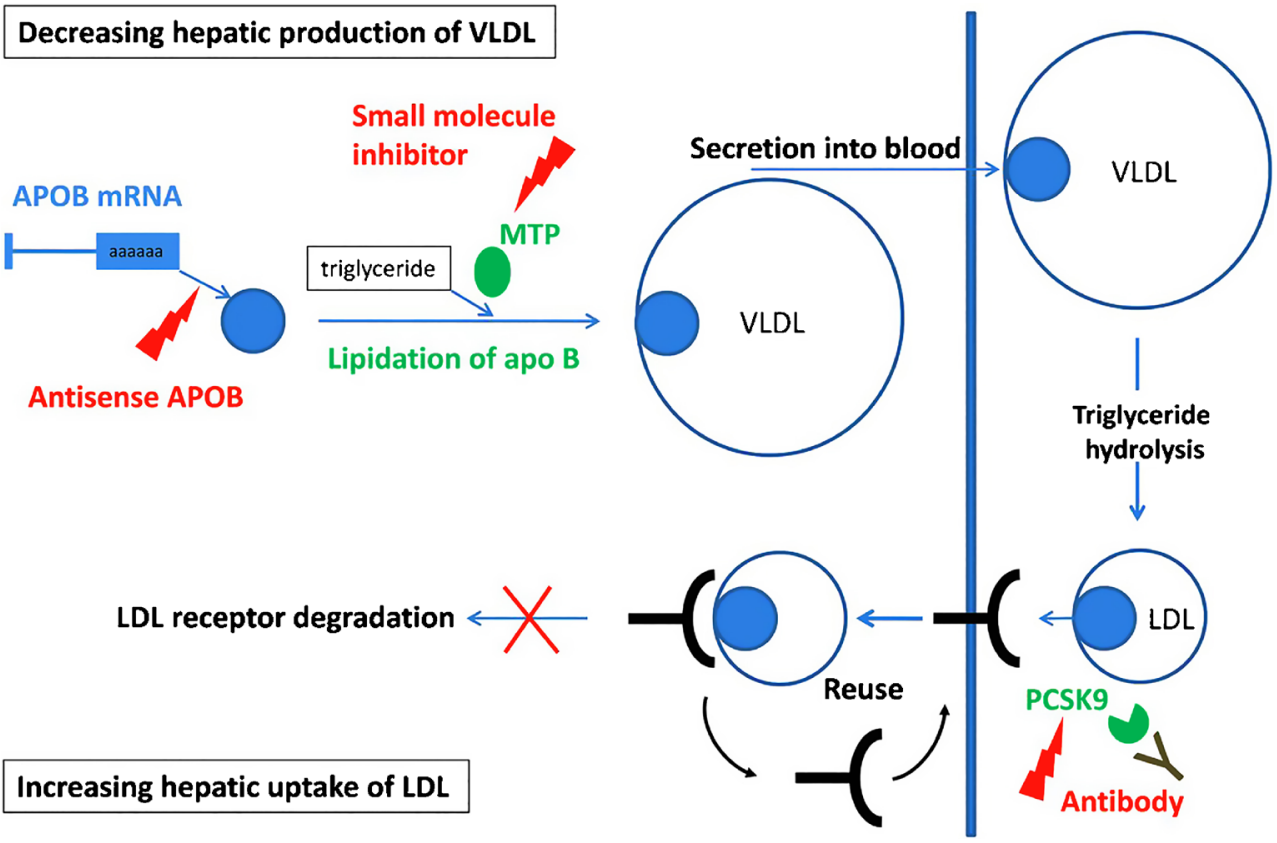


therapies $[53 \bullet, 54 \bullet]$. Both studies performed a post hoc analysis that showed evidence of a reduction in cardiovascular events $[53 \bullet, 54 \bullet]$. In a study performed in statin-intolerant patients, evolocumab performed better with regard to lowering LDL-C levels when compared to ezetimibe [55]. All monoclonal antibodies are not yet approved for general use, and only one trial has been conducted that also included HoFH children so far [56]. Long-term efficacy and safety of these agents are yet to be investigated. However, clearly, these are very promising agents in the treatment of $\mathrm{HeFH}$ either as a monotherapy or as an adjuvant therapy $[11 \bullet \bullet]$.

\section{Lomitapide}

A second novel agent is lomitapide, an oral inhibitor of the microsomal triglyceride transport protein (MTP). MTP plays an important role in the formation of ApoB-containing lipoproteins in hepatocytes and enterocytes. Inhibiting MTP therefore leads to a reduced secretion of very low-density lipoprotein (VLDL) and chylomicrons, respectively, into the circulation $[6 \bullet \bullet]$. Lomitapide has demonstrated to reduce LDL-C levels by $50 \%$ after 26 weeks of use in an open-label trial in HoFH patients already treated with lipid-lowering therapy [57]. Gastrointestinal symptoms and liver fat accumulation are the most frequently observed side effects $[57,58]$. Currently, lomitapide is only licensed for the treatment of homozygous patients as an add-on therapy by both the FDA and the EMA. In children, lomitapide has yet to be studied.

\section{Mipomersen}

Mipomersen is a second-generation antisense oligonucleotide that targets the mRNA of ApoB, thereby inhibiting its ribosomal translation $[6 \cdot \bullet, 59]$. ApoB is the main protein of LDL and its precursor VLDL; by reducing the synthesis of $\mathrm{ApoB}$, mipomersen reduces the hepatic production and secretion of VLDL [6••]. In a placebo-controlled double-blind trial in $\mathrm{HoFH}$ patients, mipomersen resulted in a $25 \%$ reduction in LDL-C from baseline [60]. In severe $\mathrm{HeFH}$ with coronary artery disease, mipomersen decreased LDL-C with $28 \%$ [61]. In addition to frequent injection side reactions, fatigue and myalgia, mipomersen can induce hepatic steatosis $[6 \bullet \bullet, 11 \bullet \bullet, 60,61]$. This agent has not been tested in children and has only been approved by the FDA, not the EMA, to be used in HoFH patients as an orphan drug.

\section{Homozygous FH}

HoFH is clinically characterized by plasma LDL-C levels $>13 \mathrm{mmol} / \mathrm{L}(>500 \mathrm{mg} / \mathrm{dL})$, extensive xanthomatas, and marked premature and progressive atherosclerotic CVD
[6••]. If not treated, most patients with these LDL-C levels will develop atherosclerosis before the age of 20 years and, most often, will not survive beyond the age of 30 [1].

True genetic homozygotes have identical mutations in both alleles of the affected gene, but most patients are compound heterozygotes with two different mutations in the LDLR, the ApoB or the PCSK9 gene $[5 \cdot, 6 \bullet \bullet$.

The severity of the clinical phenotype per patient depends on the residual LDLR activity. HoFH patients are classified as either receptor negative $(<2 \%$ residual activity) or receptor defective (2-25\% residual activity) [1, 62]. Residual activity is associated with the severity of disease; receptor-negative patients have higher LDL-C levels and poorer clinical prognosis $[6 \bullet \bullet, 63]$. Because of the aggressive nature of this disease, children who are suspected of HoFH should be referred to specialized centers as soon as possible.

To prevent or delay CVD in children with $\mathrm{HoFH}$, early and aggressive cholesterol-lowering treatment is warranted $[6 \cdot \bullet]$. Starting with a statin, with or without ezetimibe, as soon as the diagnosis is clear delays cardiovascular events and prolongs survival as shown in a retrospective cohort study [64]. Lipoprotein apheresis, if available, is an important adjunctive treatment for HoFH and can improve CHD outcome [65•]. Lipoprotein apheresis refers to all extracorporeal methods used to remove atherogenic ApoB-containing lipoproteins from the circulation [66]. A single treatment can decrease plasma LDL-C by $55-70 \%$ relative to pretreatment levels $[6 \cdot \bullet]$. This reduction, however, is temporary, and treatment once per 1 or 2 weeks is therefore desirable $[67,68]$. When performed once a week, mean LDL-C levels can come close or under target levels [6••]. Data on LDL apheresis in children is limited, but several case series and case reports show LDL apheresis to be a safe and effective treatment for $\mathrm{HoFH}$ in children [69-71]. Current guidelines recommend starting apheresis in those who need it as soon as possible, ideally by age 5 , but no later than age $8[6 \bullet \bullet$.

As mentioned earlier, lomitapide and mipomersen are recently approved by the FDA to be used as an adjunct therapy for $\mathrm{HoFH}$ in patients aged $\geq 18$ and $\geq 12$ years, respectively. With both agents, fat accumulation in the liver has been observed and the long-term consequences of the use of these agents remain unclear. Therefore, the results of long-term clinical trials need to be awaited [72].

Antibody therapies to PCSK9 could be another future option for children with HoFH. In a pilot study performed in patients with $\mathrm{HoFH}$, it was shown that in receptordefective patients, a decrease of LDL-C of $26.3 \%$ could be achieved. However, in the receptor-negative patients, no effect was seen [73]. Pediatric trials of monoclonal antibodies to PCSK9 are planned. 


\section{Conclusion}

Early identification and treatment of children with $\mathrm{FH}$ are important to prevent atherosclerosis at the earliest stage of development. Screening strategies differ across countries and depend on feasibility and local guidelines. Treatment of FH should start at a young age with lifestyle adjustments. If lifestyle changes alone are not sufficient, lipid-lowering treatment from the age of 8 is indicated, with statins as the first choice of treatment. In different short-term studies and one long-term follow-up study, statins are proven to be safe and effective. Safety, however, remains a really important issue, and more long-term follow-up studies in large cohorts are strongly recommended.

Current treatment options are not always sufficient, and new promising agents like PCSK9 inhibitors are currently being studied in phase III trials in adults. Trials with these novel agents in children are still awaited.

\section{Compliance with Ethics Guidelines}

Conflict of Interest Ilse K. Luirink, Barbara A. Hutten, and Albert Wiegman declare that they have no conflict of interest.

Human and Animal Rights and Informed Consent This article does not contain any studies with human or animal subjects performed by any of the authors.

Open Access This article is distributed under the terms of the Creative Commons Attribution 4.0 International License (http:// creativecommons.org/licenses/by/4.0/), which permits unrestricted use, distribution, and reproduction in any medium, provided you give appropriate credit to the original author(s) and the source, provide a link to the Creative Commons license, and indicate if changes were made.

\section{References}

Papers of particular interest, published recently, have been highlighted as:

- Of importance

•- Of major importance

1. Goldstein JL, Hobbs HH, Brown MS. Part 12: lipids chapter 120: familial hypercholesterolemia. In: Scriver CR, Beaudet AL, Sly WS, Valle D, editors. The metabolic and molecular bases of inherited disease. 8th ed. New York: McGraw-Hill; 2001. p. 2863-913.

2. Innerarity TL, Weisgraber KH, Arnold KAYS, Mahley RW, Kraussf RM, Vega GL, et al. Familial defective apolipoprotein B-100: low density lipoproteins with abnormal receptor binding. Proc Natl Acad Sci U S A. 1987;84:6919-23.

3. Abifadel M, Rabès J-P, Devillers M, Munnich A, Erlich D, Junien $\mathrm{C}$, et al. Mutations and polymorphisms in the proprotein convertase subtilisin kexin 9 (PCSK9) gene in cholesterol metabolism and disease. Hum Mutat. 2009;30:520-9.

4.• Nordestgaard BG, Chapman MJ, Humphries SE, et al. Familial hypercholesterolaemia is underdiagnosed and undertreated in the general population: guidance for clinicians to prevent coronary heart disease. Consensus statement of the European Atherosclerosis Society. Eur Heart J 2013:1-14. An important paper on the current underdiagnosis and undertreatment of FH in the general population.

5. Sjouke B, Kusters DM, Kindt I, Besseling J, Defesche J, Sijbrands EJG, Roeters van Lennep JE, Stalenhoef AFH, Wiegman A, de Graaf J, Fouchier SW, Kastelein JJP, Hovingh GK. Homozygous autosomal dominant hypercholesterolemia in the Netherlands: prevalence, genotype-phenotype relationship and clinical outcome. Eur Heart J 2014. This study provides insight in the genotype-phenotype relationship of HoFH.

6.• Cuchel M, Bruckert E, Ginsberg HN, et al. Homozygous familial hypercholesterolaemia: new insights and guidance for clinicians to improve detection and clinical management. A position paper from the consensus panel on familial hypercholesterolaemia of the European Atherosclerosis Society. Eur Heart J. 2014;35:2146-57. This is the most extensive consensus paper on HoFH so far.

7. Austin MA, Hutter CM, Zimmern RL, Humphries SE. Genetic causes of monogenic heterozygous familial hypercholesterolemia: a HuGE prevalence review. Am J Epidemiol. 2004;160:407-20.

8. Kusters DM, de Beaufort C, Widhalm K, Guardamagna O, Bratina $\mathrm{N}$, Ose L, et al. Paediatric screening for hypercholesterolaemia in Europe. Arch Dis Child. 2012;97(3):272-6.

9. Watts GF, Familial Hypercholesterolaemia Australasia Network Consensus Group (Australian Atherosclerosis Society). Familial hypercholesterolaemia: a model of care for Australasia. Atheroscler Suppl. 2011;12:221-63.

10. McCrindle BW, Kwiterovich PO, McBride PE, Daniels SR, Kavey RE. Guidelines for lipid screening in children and adolescents: bringing evidence to the debate. Pediatrics. 2012;130(2):353-6.

11.• Watts GF, Gidding S, Wierzbicki AS, et al. Integrated guidance on the care of familial hypercholesterolaemia from the International FH Foundation. Int J Cardiol. 2014;171:309-25. An extensive overview on the care of $\mathrm{FH}$ around the world.

12. Expert Panel on Integrated Guidelines for Cardiovascular Health and Risk Reduction in Children and Adolescents, National Heart, Lung, and Blood Institute. Expert panel on integrated guidelines for cardiovascular health and risk reduction in children and adolescents: summary report. Pediatrics. 2011;128 suppl 5:S213-56.

13. Descamps OS. Management of familial hypercholesterolemia in children and young adults: consensus paper developed by a panel of lipidologists, cardiologists, paediatricians, nutritionists, gastroenterologists, general practitioners and a patient organization. Atherosclerosis. 2011;218:272-80.

14. de Jongh S, Lilien MR, Bakker HD, Kastelein JJ, Stroes ES. Family history of cardiovascular events and endothelial dysfunction in children with familial hypercholesterolemia. Atherosclerosis. 2002;163(1):193-7.

15. Wiegman A, de Groot E, Hutten BA, Rodenburg J, Gort J, Bakker $\mathrm{HD}$, et al. Arterial intima-media thickness in children heterozygous for familial hypercholesterolaemia. Lancet. 2004;363:369-70.

16. Kusters DM, Wiegman A, Kastelein JJ, Hutten BA. Carotid intimamedia thickness in children with familial hypercholesterolemia. Circ Res. 2014;114:307-10. One of the few studies on cIMT in children with $\mathrm{FH}$, showing the early start of vessel wall thickening.

17. Biinikoski H, Lagström H, Jokinen E, Siltala M, Rönnemaa T, Viikari J, et al. Impact of repeated dietary counseling between infancy and 14 years of age on dietary intakes and serum lipids and lipoproteins: the STRIP study. Circulation. 2007;28(116):1032-40.

18. Obarzanek E, Kimm SY, Barton BA, et al. Long term safety and efficacy of a cholesterol lowering diet in children with elevated low density lipoprotein cholesterol: seven year results of the dietary intervention study in children (DISC). Pediatrics. 2001;107:25664. 
19. Amundsen AL, Ose L, Nenseter MS, Ntanios FY. Plant sterol esterenriched spread lowers plasma total and LDL cholesterol in children with familial hypercholesterolemia. Am J Clin Nutr. 2002;76: $338 \mathrm{e} 44$.

20. Malhotra A, Shafiq N, Arora A, et al. Dietary interventions (plant sterols, stanols, omega-3 fatty acids, soy protein and dietary fibers) for familial hypercholesterolaemia. Cochrane Database Syst Rev. 2014;6(6), CD001918.

21. Gylling H, Plat J, Turley S, Ginsberg HN, Ellegård L, Jessup W, et al. Plant sterols and plant stanols in the management of dyslipidaemia and prevention of cardiovascular disease. Atherosclerosis. 2014;232:346-60.

22. Pahkala K, Heinonen OJ, Simell O, Viikari JS, Rönnemaa T, Niinikoski H, et al. Association of physical activity with vascular endothelial function and intima-media thickness. Circulation. 2011;124(18):1956-63.

23. Erhardt L. Cigarette smoking: an untreated risk factor for cardiovascular disease. Atherosclerosis. 2009;205:23-32.

24. Gidding SS, Lichtenstein AH, Faith MS, Karpyn A, Mennella JA, Popkin B, et al. Implementing American Heart Association pediatric and adult nutrition guidelines: a scientific statement from the American Heart Association Nutrition Committee of the Council on Nutrition, Physical Activity and Metabolism, Council on Cardiovascular Disease in the Young, Council on Arteriosclerosis, Thrombosis and Vascular Biology, Council on Cardiovascular Nursing, Council on Epidemiology and Prevention, and Council for High Blood Pressure Research. Circulation. 2009;119:1161-75.

25. Daniels SR, Gidding SS, de Ferranti SD. Pediatric aspects of familial hypercholesterolemias: recommendations from the National Lipid Association Expert Panel on Familial Hypercholesterolemia. J Clin Lipidol. 2011;5:S30-7.

26.• Wiegman A, Gidding SS, Watts GF, et al. Familial hypercholesterolaemia in children and adolescents: gaining decades of life by optimizing detection and treatment. Eur Heart J. 2015. Latest consensus paper on the care of pediatric $\mathrm{FH}$ patients.

27. Brown MS, Goldstein JL. Multivalent feedback regulation of HMG CoA reductase, a control mechanism coordinating isoprenoid synthesis and cell growth. J Lipid Res. 1980;21:505-17.

28. Braamskamp JAM, Stefanutti C, Langslet G, Drogari E, Wiegman A, Hounslow N, Kastelein JJ. Efficacy and safety of pitavastatin at adult doses in children and adolescents between 6 and 17 years at high future cardiovascular risk. J Pediatr (in press)

29. Reiner Z. Impact of early evidence of atherosclerotic changes on early treatment in children with familial hypercholesterolemia. Circ Res. 2014;17(114):233-5.

30. Avis HJ, Vissers MN, Stein EA, Wijburg FA, Trip MD, Kastelein $\mathrm{JJ}$, et al. A systematic review and meta-analysis of statin therapy in children with familial hypercholesterolemia. Arterioscler Thromb Vasc Biol. 2007;27:1803-10.

31. Vuorio A, Kuoppala J, Kovanen PT, Humphries SE, Tonstad S, Wiegman A, et al. Statins for children with familial hypercholesterolemia. Cochrane Database Syst Rev. 2014;7, CD006401.

32. Arambepola C, Farmer AJ, Perera R, et al. Statin treatment for children and adolescents with heterozygous familial hypercholesterolaemia: a systematic review and meta-analysis. Atherosclerosis. 2007;195:339-47.

33. Thorogood M, Seed M, De Mott K, Guideline Development Group. Management of fertility in women with familial hypercholesterolaemia: summary of NICE guidance. Br J Obstet Gynaecol. 2009;116:478-9.

34. Kusters DM, Hassani Lahsinoui H, van de Post JA, Wiegman A, Wijburg FA, Kastelein JJ, et al. Statin use during pregnancy: a systematic review and meta-analysis. Expert Rev Cardiovasc Ther. 2012;10(3):363-78.

35.• Kusters DM, Avis HJ, de Groot E, Wijburg FA, Kastelein JJ, Wiegman A, et al. Ten-year follow-up after initiation of statin therapy in children with familial hypercholesterolemia. JAMA. 2014;312(10):1055-7. The longest follow-up study in patients with $\mathrm{FH}$ who started statins in childhood.

36. Sudhop T, Lütjohann D, Kodal A, Igel M, Tribble DL, Shah S, et al. Inhibition of intestinal cholesterol absorption by ezetimibe in humans. Circulation. 2002;8:106.

37. Sweeney ME, Johnson RR. Ezetimibe: an update on the mechanism of action, pharmacokinetics and recent clinical trials. Expert Opin Drug Metab Toxicol. 2007;3:441-50.

38. Martin AC, Coakley J, Forbes DA, Sullivan DR, Watts GF. Familial hypercholesterolaemia in children and adolescents: a new paediatric model of care. J Paediatr Child Health. 2013;49:E263-72.

39. Dujovne CA, Ettinger MP, McNeer JF, Lipka LJ, Lebeaut AP, Suresh R, et al. Efficacy and safety of a potent new selective cholesterol absorption inhibitor, ezetimibe, in patients with primary hypercholesterolemia. Am J Cardiol. 2002;15(90):1092-7.

40. Knopp RH, Gitter H, Truitt T, Bays H, Manion CV, Lipka LJ, et al. Effects of ezetimibe, a new cholesterol absorption inhibitor, on plasma lipids in patients with primary hypercholesterolemia. Eur Heart J. 2003;24:729-41.

41. van der Graaf A, Cuffie-Jackson C, Vissers MN, Trip MD, Gagne C, Shi G. Efficacy and safety of coadministration of ezetimibe and simvastatin in adolescents with heterozygous familial hypercholesterolemia. J Am Coll Cardiol. 2008;52:1421-9.

42. Clauss S, Wai KM, Kavey RE, Kuehl K. Ezetimibe treatment of pediatric patients with hypercholesterolemia. J Pediatr. 2009;154: 869-72.

43. Araujo MB, Botto PM, Mazza CS. Use of ezetimibe in the treatment of familial hypercholesterolemia in children and adolescents. An Pediatr (Barc). 2012;77:37-42.

44. Kusters DM, Caceres M, Coll M, Cuffie C, Gagné C, Jacobson MS, et al. Efficacy and safety of ezetimibe monotherapy in children with heterozygous familial or nonfamilial hypercholesterolemia. J Pediatr. 2015;166(6):1377-84. S0022-3476(15)00163-8.

45. West RJ, Lloyd JK, Leonard JV. Long-term follow-up of children with familial hypercholesterolaemia treated with cholestyramine. Lancet. 1980;2:873-5.

46. Stein EA, Marais AD, Szamosi T, Raal FJ, Schurr D, Urbina EM, et al. Colesevelam hydrochloride: efficacy and safety in pediatric subjects with heterozygous familial hypercholesterolemia. J Pediatr. 2010;156:231-6.

47. Perry CM. Colesevelam: in pediatric patients with heterozygous familial hypercholesterolemia. Paediatr Drugs. 2010;12:133-40.

48. Davidson MH. A systematic review of bile acid sequestrant therapy in children with familial hypercholesterolemia. J Clin Lipidol. 2011;5:76-81.

49. Pijlman AH, Huijgen R, Verhagen SN, et al. Evaluation of cholesterol lowering treatment of patients with familial hypercholesterolemia: a large cross-sectional study in the Netherlands. Atherosclerosis. 2010;209:189-94.

50. Seidah NG. Proprotein convertase subtilisin kexin 9 (PCSK9) inhibitors in the treatment of hypercholesterolemia and other pathologies. Curr Pharm Des. 2013;19:3161-72.

51. Sniderman AD, Tsimikas S, Fazio S. The severe hypercholesterolemia phenotype: clinical diagnosis, management, and emerging therapies. J Am Coll Cardiol. 2014;63:1935-47.

52. Benjannet $\mathrm{S}$, Hamelin J, Chretien M, Seidah NG. Loss-and gain of function PCSK9 variants: cleavage specificity, dominant negative effects, and low density lipoprotein receptor (LDLR) degradation. J Biol Chem. 2012;28;287(40):33745-55.

53. Robinson JG et al. Efficacy and safety of alirocumab in reducing lipids and cardiovascular events. N Engl J Med. 2015;372:1489-99. Important study on monoclonal antibodies against PCSK9 in adults.

54. Sabatine MS et al. Efficacy and safety of evolocumab in reducing lipids and cardiovascular events. N Engl J Med. 2015;372:1500-9. 
Important study on monoclonal antibodies against PCSK9 in adults.

55. Stroes E, Colquhoun D, Sullivan D, Civeira F, Rosenson RS, Watts GF, Bruckert E, Cho L, Dent R, Knusel B, Xue A, Scott R, Wasserman SM, Rocco M; GAUSS-2 Investigators. Anti-PCSK9 antibody effectively lowers cholesterol in patients with statin intolerance: the GAUSS-2 randomized, placebo-controlled phase 3 clinical trial evolocumab.

56. Raal FJ et al. Inhibition of PCSK9 with evolocumab in homozygous familial hypercholesterolaemia (TESLA part B): a randomized, double-blind, placebo-controlled trial. Lancet. 2015;385: 341-50.

57. Cuchel M, Meagher EA, du Toit TH, Blom DJ, Marais AD, Hegele RA, et al. Efficacy and safety of a microsomal triglyceride transfer protein inhibitor in patients with homozygous familial hypercholesterolaemia: a single-arm, open-label, phase 3 study. Lancet. 2013;381:40-6.

58. Cuchel M, Blom DJ, Averna MR. Clinical experience of lomitapide therapy in patients with homozygous familial hypercholesterolaemia. Atheroscler Suppl. 2014;15:33-45.

59. Crooke ST, Geary RS. Clinical pharmacological properties of mipomersen (Kynamro), a second generation antisense inhibitor of apolipoprotein B. Br J Clin Pharmacol. 2013;76(2):269-76.

60. Raal FJ, Santos RD, Blom DJ, et al. Mipomersen, an apolipoprotein B synthesis inhibitor, for lowering of LDL cholesterol concentrations in patients with homozygous familial hypercholesterolaemia: a randomised, double-blind, placebo-controlled trial. Lancet. 2010;375:998-1006.

61. Stein EA, Dufour R, Gagne C, et al. Apolipoprotein B synthesis inhibition with mipomersen in heterozygous familial hypercholesterolemia clinical perspective: results of a randomized, doubleblind, placebo-controlled trial to assess efficacy and safety as addon therapy in patients with coronary artery disease. Circulation. 2012;126:2283-92.

62. Hobbs HH, Brown MS, Goldstein JL. Molecular genetics of the LDL receptor gene in familial hypercholesterolemia. Hum Mutat. 1992;1:445-66.

63. Kolansky DM, Cuchel M, Clark BJ, Paridon S, McCrindle BW, Wiegers SE, et al. Longitudinal evaluation and assessment of cardiovascular disease in patients with homozygous familial hypercholesterolemia. Am J Cardiol. 2008;102(11):1438-43.
64. Raal FJ, Pilcher GJ, Panz VR, van Deventer HE, Brice BC, Blom DJ, et al. Reduction in mortality in subjects with homozygous familial hypercholesterolemia associated with advances in lipidlowering therapy. Circulation. 2011;124:2202-7.

65. Thompson GR. The evidence-base for the efficacy of lipoprotein apheresis in combating cardiovascular disease. Atheroscler Suppl. 2013;14:67-70. Important overview article on LDL apheresis.

66. Page MM, Bell DA, Hooper AJ, Watts GF, Burnett JR. Lipoprotein apheresis and new therapies for severe familial hypercholesterolemia in adults and children. Best Pract Res Clin Endocrinol Metab. 2014;28(3):387-403.

67. Thompson GR, HEART-UK LDL Apheresis Working Group. Recommendations for the use of LDL apheresis. Atherosclerosis. 2008;198(2):247-55.

68. Stefanutti C, Julius U. Lipoprotein apheresis: state of the art and novelties. Atheroscler Suppl. 2013;14(1):19-27.

69. Dann EJ, Shamir R, Mashiach T, Shaoul R, Badian A, Stravets T, Kerzman Y, Finkelbaum S, Gaitini D, Lorber A, Bonstein L. Earlyonset plasmapheresis and LDL-apheresis provide better disease control for pediatric homozygous familial hypercholesterolemia than $\mathrm{HMG}-\mathrm{Co} A$ reductase inhibitors and ameliorate atherosclerosis.

70. Græsdal A, Bogsrud MP, Holven KB, Nenseter MS, Narverud I, Langslet G, et al. Apheresis in homozygous familial hypercholesterolemia: the results of a follow-up of all Norwegian patients with homozygous familial hypercholesterolemia. J Clin Lipidol. 2012;6(4):331-9.

71. Palcoux JB, Atassi-Dumont M, Lefevre P, Hequet O, Schlienger JL, Brignon $\mathrm{P}$, et al. Low-density lipoprotein apheresis in children with familial hypercholesterolemia: follow-up to 21 years. Ther Apher Dial. 2008;12(3):195-201.

72. Sjouke B, Hovingh KG, Kastelein JJ, Stefanutti C. Homozygous autosomal dominant hypercholesterolemia: prevalence, diagnosis, and current and future treatment perspectives. Curr Opin Lipidol. 2015.

73. Stein EA, Honarpour N, Wasserman SM, Xu F, Scott R, Raal FJ. Effect of the proprotein convertase subtilisin/kexin 9 monoclonal antibody, AMG 145, in homozygous familial hypercholesterolemia. Circulation. 2013;128(19):2113-20. 